\title{
Cognitive performance in distinct groups of children undergoing epilepsy surgery - a single-centre experience
}

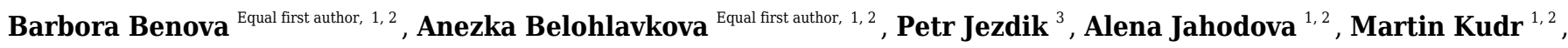 \\ Vladimir Komarek ${ }^{1,2}$, Vilem Novak ${ }^{1,4}$, Petr Liby ${ }^{5}$, Robert Lesko ${ }^{1,5}$, Michal Tichy ${ }^{1,5}$, Martin Kyncl ${ }^{1,6}$, Josef \\ Zamecnik $^{1,7}$, Pavel Krsek ${ }^{\text {Corresp., }, 2, \text { Alice Maulisova }}{ }^{8}$ \\ 1 2nd faculty of medicine, Charles University Prague, Prague, Czech Republic \\ 2 Department of Paediatric Neurology, Motol University Hospital, Prague, Czech Republic \\ 3 Faculty of Electrical Engineering, Department of Circuit Theory, Czech Technical University of Prague, Prague, Czech Republic \\ 4 Department of Paediatric Neurology, Ostrava Faculty Hospital, Ostrava, Czech Republic \\ 5 Department of Neurosurgery, Motol University Hospital, Prague, Czech Republic \\ 6 Department of Radiology, Motol Universiy Hospital, Prague, Czech Republic \\ 7 Department of Pathology and Molecular Medicine, Motol University Hospital, Prague, Czech Republic \\ 8 Department of Clinical Psychology, Motol University Hospital, Prague, Czech Republic \\ Corresponding Author: Pavel Krsek \\ Email address: pavel.krsek@fnmotol.cz
}

Background. We aimed first to describe trends in cognitive performance over time in a large patient cohort $(n=203)$ from a single tertiary centre for paediatric epilepsy surgery over the period of 16 years divided in two (developing - pre-2011 vs. established - post-2011). Secondly, we tried to identify subgroups of epilepsy surgery candidates with distinctive epilepsy-related characteristics that associate with their pre- and post- surgical cognitive performance. Thirdly, we analysed variables affecting presurgical and post-surgical IQ/DQ and their change(post- vs. pre-surgical).

Methods. We analysed IQ/DQ data obtained using standardized neuropsychological tests before epilepsy surgery and one year post-surgically, along with details of patient's epilepsy, epilepsy surgery and outcomes in terms of freedom from seizures. Using regression analysis, we described the trend in post-operative IQ/DQ. Cognitive outcomes and the associated epilepsy- and epilepsy surgery-related variables were compared between periods before and after 2011. Using multivariate analysis we analysed the effect of individual variables on pre- and post-operative IQ/DQ and its change.

Results. Epilepsy surgery tends to improve post-surgical IQ/DQ, most significantly in patients with lower pre-surgical IQ/DQ, and post-surgical IQ/DQ strongly correlates with pre-surgical IQ/DQ (Rho=0.888, $p<0.001)$. We found no significant difference in pre-, post-surgical IQ/DQ and IQ/DQ change between the periods of pre-2011 and post-2011 ( $p=0.7, p=0.469, p=0.796$, respectively). Patients with temporal or extratemporal epilepsy differed in their pre-surgical IQ/DQ $(p=0.001)$ and in IQ/DQ change $(p=0.002)$ from those with hemispheric epilepsy, with no significant difference in post-surgical IQ/DQ $(p=0.888)$. Groups of patients with different underlying histopathology showed significantly different pre- and post-surgical IQ/DQ ( $p<0.001$ and $p<0.001$ respectively) but not IQ/DQ change $(p=0.345)$.Variables associated with severe epilepsy showed effect on cognitive performance in multivariate model.

Discussion. Post-surgical IQ/DQ strongly correlates with pre-surgical IQ/DQ and greatest IQ/DQ gain occurs in patients with lower pre-surgical IQ/DQ scores. Cognitive performance was not affected by changes in paediatric epilepsy surgery practice. Pre- and post-operative cognitive performances, as well 
as patients' potential for cognitive recovery, are highly dependent on the underlying aetiology and epileptic syndrome. 


\section{Cognitive performance in distinct groups of children undergoing epilepsy surgery-a single-centre experience}

Barbora Benova ${ }^{1,8^{*}}$, Anezka Belohlavkova ${ }^{1,8^{*}}$, Petr Jezdik ${ }^{2}$, Alena Jahodova ${ }^{1,8}$, Martin Kudr ${ }^{1,8}$, Vladimir Komarek ${ }^{1,8}$, Vilem Novak ${ }^{7,8}$, Petr Liby ${ }^{4}$, Robert Lesko ${ }^{4}$, Michal Tichy ${ }^{4}$, Martin $\mathrm{Kyncl}^{5,8}$, Josef Zamecnik ${ }^{6,8}$, Pavel Krsek $^{1,8}$, Alice Maulisova ${ }^{3}$

1: 2nd faculty of medicine, Charles University Prague, Prague, Czech Republic

2: Department of Paediatric Neurology, Motol University Hospital, Prague, Czech Republic

3: Faculty of Electrical Engineering, Department of Circuit Theory, Czech Technical University of Prague, Prague, Czech Republic

4: Department of Paediatric Neurology, Ostrava Faculty Hospital, Ostrava, Czech Republic

5: Department of Neurosurgery, Motol University Hospital, Prague, Czech Republic

6: Department of Radiology, Motol Universiy Hospital, Prague, Czech Republic

7: Department of Pathology and Molecular Medicine, Motol University Hospital, Prague, Czech Republic

8: Department of Clinical Psychology, Motol University Hospital, Prague, Czech Republic

*These authors contributed equally to this work.

\section{Corresponding author:}

Prof. Pavel Kršek, M.D., Ph.D.

Head of department

Department of Pediatric Neurology

Motol Epilepsy Center

Charles University in Prague, 2nd Faculty of Medicine

Motol University Hospital

V Úvalu 84, 15006 - Prague 5

Czech Republic

Phone: +420 224433300

Fax: +420 224433322

E-mail: pavel.krsek@post.cz 


\begin{abstract}
:
48

49

50

51

52

53

54

55

Background. We aimed first to describe trends in cognitive performance over time in a large patient cohort $(n=203)$ from a single tertiary centre for paediatric epilepsy surgery over the period of 16 years divided in two (developing - pre-2011 vs. established - post-2011). Secondly, we tried to identify subgroups of epilepsy surgery candidates with distinctive epilepsy-related characteristics that associate with their pre- and post- surgical cognitive performance. Thirdly, we analysed variables affecting pre-surgical and post-surgical IQ/DQ and their change(post- vs. pre-surgical).

Methods. We analysed IQ/DQ data obtained using standardized neuropsychological tests before epilepsy surgery and one year post-surgically, along with details of patient's epilepsy, epilepsy surgery and outcomes in terms of freedom from seizures. Using regression analysis, we described the trend in post-operative IQ/DQ. Cognitive outcomes and the associated epilepsyand epilepsy surgery-related variables were compared between periods before and after 2011. Using multivariate analysis we analysed the effect of individual variables on pre- and postoperative IQ/DQ and its change.

Results. Epilepsy surgery tends to improve post-surgical IQ/DQ, most significantly in patients with lower pre-surgical IQ/DQ, and post-surgical IQ/DQ strongly correlates with pre-surgical $\mathrm{IQ} / \mathrm{DQ}(\mathrm{Rho}=0.888, p<0.001)$. We found no significant difference in pre-, post-surgical IQ/DQ and IQ/DQ change between the periods of pre-2011 and post-2011 ( $p=0.7, p=0.469, p=0.796$, respectively). Patients with temporal or extratemporal epilepsy differed in their pre-surgical $\mathrm{IQ} / \mathrm{DQ}(p=0.001)$ and in IQ/DQ change $(p=0.002)$ from those with hemispheric epilepsy, with no significant difference in post-surgical IQ/DQ $(p=0.888)$. Groups of patients with different underlying histopathology showed significantly different pre- and post-surgical IQ/DQ $(p<0.001$ and $p<0.001$ respectively) but not IQ/DQ change $(p=0.345)$. Variables associated with severe epilepsy showed effect on cognitive performance in multivariate model.

Discussion. Post-surgical IQ/DQ strongly correlates with pre-surgical IQ/DQ and greatest IQ/DQ gain occurs in patients with lower pre-surgical IQ/DQ scores. Cognitive performance was not affected by changes in paediatric epilepsy surgery practice. Pre- and post-operative cognitive performances, as well as patients' potential for cognitive recovery, are highly dependent on the underlying aetiology and epileptic syndrome.
\end{abstract}


93

94

95

96

97

98

\section{Introduction}

Epilepsy surgery represents an established method for treatment of focal drug resistant epilepsy in both children and adults (Ryvlin et al. 2014). The major aims of paediatric epilepsy surgery are: to relieve the patient of debilitating seizures and anti-epileptic medication, or at least to significantly decrease seizure frequency, and to prevent further decline in developmental/cognitive functions, often accompanying drug resistant epilepsy (Freitag \& Tuxhorn 2005; Moosa \& Wyllie 2017). In the past few decades, the outcome in terms of freedom from seizures has either tended to improve (Hemb et al. 2010), or remained stable (Lamberink et al. 2015) in large paediatric epilepsy surgery centres. Freedom from seizures has repeatedly been associated with favourable cognitive outcome (Puka et al. 2017; Van Schooneveld \& Braun 2013; Viggedal et al. 2013), even with catch-up in mental development (Freitag \& Tuxhorn 2005).

In an extensive review (Van Schooneveld \& Braun 2013), multiple pre-, post-surgical and surgery-related variables affecting cognitive performance before and after epilepsy surgery were identified, including epilepsy duration, underlying aetiology, age at surgery, seizure outcome, etc. Multiple additional factors play their role in cognitive development of children with focal structural epilepsy, such as the extent of the epileptogenic zone and of the zone of dysfunction, the epileptiform discharges and the effects of antiepileptic medication. Their interacting effects may influence patients' long-term prognosis to achieve freedom from seizures and optimal cognitive development (Moosa \& Wyllie 2017).

Longitudinal studies on seizure outcomes of children undergoing epilepsy surgery compared seizure outcomes between early vs. late period of the epilepsy surgery program (Hemb et al. 2010; Lamberink et al. 2015). The results reflected changes in epilepsy surgery practice: the 
116 advent of novel diagnostic methods (magnetoencephalography, post-processing neuroimaging

117 methods, source imagingand others) and improved surgical techniques (e.g. increased use of

118 stereo-EEG). However, none of these studies focused on differences in cognitive outcomes

119 between the two periods.

120 Most studies on cognitive outcomes of paediatric epilepsy surgery patients have been limited to

121 small patients series even though over a long follow-up period (Viggedal et al. 2012) or to

122 specific subgroups, e.g. patients with low IQ (Malmgren et al. 2008), preschool children (Freitag

$123 \&$ Tuxhorn 2005), children undergoing hemispherotomy for hemimegalencephaly (Honda et al.

124 2013). Skirrow et al. analysed cognitive outcomes in children with temporal lobe epilepsy and

125 provided evidence that resective epilepsy surgery leads to long-term cognitive improvement,

126 compared to medical treatment only (Skirrow et al. 2011). Lee et al. showed that even patients

127 with severe epileptic encephalopathy, incl. Lennox-Gastaut and West syndrome, may profit from

128 epilepsy surgery both in terms of seizure and cognitive outcome; in $73.5 \%$ of cases

129 malformations of cortical development (MCD) represented the underlying aetiology (Lee et al.

130 2014). Honda et al. have proven the positive effect of early hemispherotomy for

131 hemimegalencephaly on developmental outcome of post-surgically seizure-free children (Honda

132 et al. 2013).

133 A more recent longitudinal study (Sibilia et al. 2017) followed 31 children who underwent

134 epilepsy surgery and a control group of 14 medically treated paediatric epilepsy surgery

135 candidates and found no significant difference between the groups in IQ/DQ both at the

136 beginning of the study and after two years of follow-up. The developmental trajectories,

137 however, differed, and patients in the surgical group improved, while patients in the conservative

138 group showed decrease in IQ/DQ over the two-year period. The main limitation of this study, 
139 however, remains its small sample size. The problems of sample size and the length of follow-up

140 period were addressed in another longitudinal study (Puka et al. 2017) that analysed cognitive

141 performance in a surgical and a non-surgical group of 97 paediatric epilepsy patients and

142 unexpectedly found no difference in cognitive performance between the groups after a follow-up

143 period of 4 to 11 years. The control group, however, was quite heterogeneous, combining

144 potential surgical candidates who refused surgery and those who were not indicated for epilepsy

145 surgery in the first place, with varying aetiologies.

146 To summarize, many studies on cognitive outcomes in paediatric epilepsy surgery patients are

147 limited by small sample size, short follow-up period, and they often fail to distinguish patients'

148 cognitive abilities according to the underlying aetiology.

149 In this study we aimed first to analyse trends in cognitive profiles of children undergoing 150 epilepsy surgery over the period of 17 years and to test whether there were differences in 151 cognitive performance (pre-surgical IQ, post-surgical IQ, or change from pre-surgical to post152 surgical IQ) between the early and late period of the paediatric epilepsy surgery program in our 153 tertiary clinic. Next, we assessed whether there were differences in cognitive performance

154 between the early and the late period for specific underlying aetiologies and epilepsy syndromes.

155 Finally, we aimed to identify variables affecting cognitive performance in the entire cohort.

156 Materials \&Methods

157 Patient Selection

158 Paediatric patients ( $\leq 19$ years of age) investigated for and having undergone epilepsy surgery in 159 Motol Epilepsy Centre between January 1 $1^{\text {st }}, 2000$ and December 31 ${ }^{\text {st }}, 2017$ with available data 160 on (i) results of pre- and post-surgical neuropsychological evaluation, (ii) seizure outcome one 161 year after epilepsy surgery in patients included in analysis of post-surgical IQ/DQ and on (iii) 
162 pre- and post-surgical epilepsy- and epilepsy surgery-related variables were included in the 163 study. Patients who underwent multiple epilepsy surgeries were excluded. The dataset was

164 completed to our best knowledge; however, due to the nature and length of the study, some data

165 might have been missed. Since the study is observational in nature and no experimental

166 procedures were performed, the approval of Motol University Hospital ethics committee was not

167 required. Informed consent with the pre-surgical evaluation and epilepsy surgery was obtained

168 prior to all procedures from patients or their legal representatives.

169 Study Design

170 We retrospectively analysed pre-, post-surgical IQ/DQ and the change between post- and pre-

171 surgical IQ/DQ in relation to multiple epilepsy- and epilepsy surgery-related variables. In

172 addition, the study period was divided in two - pre-2011 and post-2011 - to compare trends in

173 cognitive outcomes between the periods of developing vs. established epilepsy surgery program,

174 similar to methodology published elsewhere (Lamberink et al. 2015). The cut-off date was set to

175 December 31 3 st 2010 . The year 2011 was chosen as the dividing line for several reasons: it was

176 marked by the introduction of stereo-EEG as a method of long-term invasive EEG monitoring in

177 our centre, and the number of epilepsy surgery procedures stabilized after the previously

178 observed increase every year (Belohlavkova et al. 2019).

179 By comparing two periods of epilepsy surgery program, we aimed to analyse whether changes in 180 patient population (e.g. different distribution of aetiologies, epileptic syndrome, age at surgery, 181 etc.) and novel diagnostic and treatment strategies (e.g. use of stereo-EEG and advances in 182 neuroimaging) that we report elsewhere (Belohlavkova et al. 2019)were reflected in cognitive 183 performance of patients included in the study. All studied epilepsy-related variables are listed in 184 Supplementary materials. Solely for the purpose of this study we used the term "epileptic 
185 syndrome" to denote either temporal, or extratemporal or hemispheric electro-clinical epileptic

186 syndrome without any relationship to the underlying structural or genetic aetiology;

187 hypothalamic hamartomas were excluded for the purpose of analysis of epileptic syndromes.

188 "Abnormal neurological finding" stands for any focal abnormality in standard neurological

189 examination. Surgery type represents the type of epilepsy surgery procedure:

190 hemispherectomy/hemispherotomy, tailored resection, lesionectomy, extended lesionectomy,

191 standardized resection (in our series exclusively anterior mesial temporal resection); surgery

192 extent denotes the extent of resection: hemispheric, focal, lobar or multilobar. Surgery location

193 may be either left-, right-sided or midline (hypothalamic hamartomas were preserved for this

194 analysis). Complications related to epilepsy surgery were classified as major or minor as

195 published elsewhere (Bjellvi et al. 2015). Types of focal cortical dysplasia (FCD) were classified

196 according to ILAE consensus classification (Blumcke et al. 2011). FCD type Ia, Ib and Ic are

197 characterized by abnormalities in radial, tangential and radial and tangential migration. FCD type

198 IIa and IIb display cytological abnormalities, including dysmorphic neurons (FCD IIa and IIb)

199 and balloon cells (FCD IIb). FCD type III occurs adjacent to another pathology: hippocampal

200 sclerosis (FCD IIIa), glial or glioneural tumour (FCD IIIb), vascular malformation (FCD IIIc) or

201 lesion acquired early in life (FCD IIId) (Blumcke et al. 2011). In one type of analysis,

202 histopathological lesions were divided in two groups: developmental vs. acquired. MCD, TSC

203 and long-term epilepsy-associated tumours (LEAT) were considered developmental, and

204 inflammatory, post-traumatic and glial scar lesions were considered acquired. Specifically for the

205 purpose of this analysis, hippocampal sclerosis was excluded, as the proportion of its

206 developmental or acquired origin has not yet been unequivocally established. 
207 Neuropsychological examination was performed before the (first) surgery and at one year

208 follow-up after the resection using (according to patient's age and cognitive level) Wechsler

209 Adult Intelligence Scale in 3rd revision(Wechsler 2010), Wechsler Intelligence Scale for

210 Children in 3rd revision(Wechsler 2002)for evaluating IQ and Bayley Scales of Infant

211 Development in 2nd revision(Bayley 1993) for developmental quotient assessment. Stanford-

212 Binet Intelligence Scale in 4th revision (Thorndike 1986) was selected for IQ testing in children

213 with lower cognitive skills (expected IQ<60), despite its limited reproducibility and reliability of

214 IQ testing in this group of patients.

215 Statistical Procedures

216 Pre-surgical and post-surgical IQ/DQ and IQ/DQ change scores were selected as dependent

217 variables. We first performed regression analysis to describe the relationship between pre- and

218 post-surgical IQ/DQ in the entire cohort and separately for children above and below 6 years of

219 age and for children above and below 12 years of age. Then, we did univariate regression

220 analysis for continuous observed (independent) variables and selected those with $p$-value below

2210.05 for multivariate analysis. We performed one-way ANOVA for categorical variables and

222 calculated median difference and its 95\% confidence interval using Hodges-Lehman estimator.

223 For calculation of effect sizes, omega-squared effect size was used for ANOVA tests and r-

224 squared effect size for correlation tests and multivariant models.

225 In the multivariate analysis, we calculated a multiple regression based on the general linear

226 modelby stepwise

227 regression algorithm with the variables that reached statistical significance in univariate testing.

228 The beta coefficients with $p$-values of $<0.05$ were considered statistically significant. For the

229 calculations software MatLab version 2017b and its statistical computing toolbox was used. 


\section{Results}

232

233

234

235

236

237

238

239

240

241

242

243

244

245

246

247

248

249

250

251

252

A total of 203 patients were included in the study (103 males, 100 females). For patients' details see Supplementary materials and Table 1. After accounting for the missing data, 191 patients were included in the analyses of pre-surgical IQ/DQ, 156 patients of post-surgical IQ/DQ and 154 of IQ/DQ change.

Trends in cognitive performance in the periods of pre-2011 vs. post-2011

Using regression analysis, we have shown there exists strong and significant correlation between pre- and post-surgical IQ/DQ, and that patients undergoing epilepsy surgery tend to have higher post-surgical IQ/DQ than pre-surgical IQ/DQ (Rho=0.888, $p<0.001)$. The gain in IQ/DQ is more prominent in those with lower pre-surgical IQ/DQ and the group of children older than 6 years of age (Fig 1). We found no significant difference in pre-, post-surgical IQ/DQ and IQ/DQ change between the periods of pre-2011 and post-2011 ( $p=0.62, p=0.65, p=0.77$, respectively). When analysed in groups according to the epileptic syndrome, differences in cognitive performance (pre-, post-surgical IQ/DQ and IQ/DQ change) between the two periods (pre-2011 vs. post-2011) were not significant for groups of patients with temporal lobe epilepsy (TLE), extratemporal (XTLE) and with hemispheric (HEMI) epilepsy. The same is true in relation to underlying histopathology and developmental vs. acquired lesions (see Supplementary materials). In the analysis of differences between the two periods, we classified FCD in three classes (FCD type I, FCD type II, FCD type III) as the small numbers in respective subcategories (FCD type Ia-Ic, IIa and IIb and IIIa-IIId) would preclude statistical calculation. We found a significantly lower preand post-surgical IQ/DQ in the period post-2011 $(\mathrm{F}=8.28, p=0.013$ and $\mathrm{F}=4.76, p=0.05$, respectively) in the group of FCD type I. We did not identify significant difference in post- 
253 surgical IQ/DQ and IQ/DQ change between the two periods in either seizure-free or non-seizure-

254 free patient cohort (seizure free: $\mathrm{F}=0.48 p=0.49$ and $\mathrm{F}=0.24, p=0.62$, respectively, non-seizure-

255 free: $\mathrm{F}=0.8 p=0.38$ and $\mathrm{F}=0.26 p=0.62$ ). For statistical details, including measures of effect size

256 and degrees of freedom, see Supplementary materials.

257 Pre- and post- surgical cognitive performance in distinct groups of patients according to their

258 epilepsy-related features

259 Using ANOVA statistics we observed that patients with TLE differ from those with XTLE and

260 those with HEMI epilepsy in their pre-surgical IQ/DQ $(\mathrm{F}=6.83, p=0.001)$ and in their IQ/DQ

261 change $(\mathrm{F}=6.63, p=0.002)$; post-hoc tests showed that patients with HEMI score significantly

262 lower in their IQ/DQ compared to those with XTLE and TLE (Fig2). Depending on their

263 underlying histopathology, the analyses have identified group differences in pre- and post-

264 surgical IQ/DQ $(\mathrm{F}=6.56, p<0.001$ and $\mathrm{F}=7.44, p<0.001$, respectively). Post-hoc analyses found

265 significantly higher pre-surgical IQ/DQ in patients with tumour (LEAT) compared to those with

$266 \operatorname{MCD}(p=0.002), \operatorname{TSC}(p<0,001)$ and glial scar $(p=0.005)$. Significant differences in post-surgical

267 IQ/DQ were also observed between the aetiological sub-groups; patients with LEAT achieve

268 significantly higher IQ/DQ scores than those with e.g. MCD, TSC, and those with hippocampal

269 sclerosis score higher than patients with TSC. When comparing developmental vs. acquired

270 histopathological lesions we found no significant difference in their pre-, post-surgical IQ/DQ

271 and IQ/DQ change (data not shown). Furthermore, we analysed the differences in cognitive

272 performance relative to FCD classes (Blumcke et al. 2011), and found significant difference

273 between the classes in the pre- and post-surgical IQ/DQ $(\mathrm{F}=4.89, p<0.001$ and $\mathrm{F}=4.73, p<0.001$,

274 respectively); the results remained significant for post-surgical IQ/DQ for the classes of FCD 
275 type I, II and III $(\mathrm{F}=6.32, p=0.003)$. We observed a trend towards higher pre-surgical IQ/DQ and

276 IQ/DQ change in FCD type III vs. FCD type II and type I (Fig1).

277 Predictors of pre- and post-surgical IQ/DQ and its change over the entire period

278 The results of univariate testing are listed in Table 2 for categorical variables and in Table 3 for

279 continuous variables associated with pre-surgical IQ/DQ, post-surgical IQ/DQ and IQ/DQ

280 change; only the variables significant in univariate testing are shown here, all studied variables

281 are listed in Supplementary materials. The used stepwise regression algorithm excludes variables

282 that might skew results in the calculation process of the multiple regression based on the general

283 linear model; therefore, some variables, despite being significant in univariate testing, do not

284 appear in the results of multivariate testing, listed in Table 4. Some variables associated with

285 severe epilepsy, e.g. the presence of infantile spasms affecting pre-surgical IQ/DQ remained

286 significant in univariate testing only. The factors found significant in multiple regression model

287 were (i) the presence of abnormal neurological finding and FCD type IIb and IIIb and younger

288 age at first seizure affecting pre-surgical IQ/DQ; (ii) age at first seizure, status epilepticus,

289 multilobar resection, unilobar resection, complete resection and TSC affecting post-surgical

290 IQ/DQ; (iii) age at surgery and temporal or extratemporal epileptic syndrome affecting IQ/DQ

291 change (see Table 4). The date of surgery, reflecting change in epilepsy surgery practice, was not

292 rendered significant in the multivariate regression analysis model and was therefore excluded

293 from the model by the used stepwise algorithm.

294 For the summary of statistically significant results of all tests, including post-hoc analyses and

295 the respective $p$ values, F values, effect sizes and degrees of freedom, see Tables 1-5.

296 Discussion 
297 In the period of 2000-2017 we collected data on 203 children who underwent resective epilepsy

298 surgery in the paediatric part of Motol Epilepsy Centre and studied their cognitive performance

299 in relation to the epilepsy- and epilepsy surgery-related characteristics and seizure outcome.

300 We have observed a strong correlation between the pre- and post-surgical IQ/DQ, in accordance

301 with multiple previous studies that have shown pre-surgical IQ/DQ to be a strong independent

302 predictor of post-surgical IQ/DQ (Puka et al. 2017; Van Schooneveld \& Braun 2013). Our results

303 also confirm previously reported observations that epilepsy surgery leads to greater increase in

304 IQ/DQ in children with lower pre-surgical IQ/DQ (Puka et al. 2017). Loddenkemper et al. have

305 shown similar results in infants $<3$ years of age who presented with lower DQ scores and

306 infantile spasms and achieved significantly higher DQ scores after surgery. The increase

307 however was especially prominent in children operated on before 1 year of age (Loddenkemper

308 et al. 2007). The authors suggest the increase might result from the fact that the deleterious

309 epileptic activity had been terminated early enough to impede development. Therefore, we

310 presume, it is not the value of IQ/DQ per se that leads to cognitive improvement after surgery

311 but rather the early indication of epilepsy surgery in infants presenting with severe epilepsy and

312 developmental delay. Cognitive performance of children who enter epilepsy surgery programs

313 with normal or above-average IQ tends neither to improve, nor to worsen with epilepsy surgery.

314 Although the actual numerical increase in IQ/DQ scores did not reach clinically significant

315 values of 8-15 points (Van Schooneveld \& Braun 2013), based on the regression curve equation,

316 this might have been mostly due to the limited follow-up period. Our results however, are in line

317 with other studies showing that IQ/DQ scores tend to remain stable or improve after epilepsy

318 surgery in children over a broad spectrum of cognitive performance, and even children with low

319 pre-surgical IQ/DQ do not lose cognitive skills but rather benefit from epilepsy surgery 
320 (Loddenkemper et al. 2007; Viggedal et al. 2012; Viggedal et al. 2013). Unexpectedly, we

321 observed greater gain in IQ/DQ scores in children above 6 years of age (Fig. 1), compared to

322 their younger counterparts. Given that these children were operated on later, they also might

323 have had later epilepsy onset, and the effect of drug resistant seizures was not present in early

324 sensitive periods of brain development. Also, the group of children below 6 years of age was

325 rather small which might have skewed the results. In addition, the effect of repeated

326 measurement cannot be completely ruled out (Sherman et al. 2003).

327 Cognitive performance in children undergoing epilepsy surgery did not change between the

328 periods of pre-2011 and post-2011

329 Comparing cognitive performance of all epilepsy surgery patients from the period of pre-2011

330 vs. post-2011 their pre-, post-surgical IQ/DQ and IQ/DQ change scores did not differ

331 significantly. These findings might imply that the spectrum of epilepsy surgery patients has not

332 changed significantly with respect to their cognitive performance. We further analysed whether

333 distinct groups of patients in terms of epileptic syndrome and underlying aetiology differed in

334 their cognitive performance between the two studied periods and again found no significant

335 difference. These results reflect in part the development of paediatric epilepsy surgery practice in

336 the region and in Europe (Baud et al. 2018); we are seeing increased referral of more complex

337 patients and a changing population of paediatric epilepsy surgery candidates. While in the early

338 period we encountered either very severe cases (epilepsy surgery as "the last resort") or very

339 straightforward ones (e.g. hippocampal sclerosis) with a very broad span of cognitive

340 performance, in the later period we observed a decline in the straightforward cases (such as

341 hippocampal sclerosis) and an increase in timely referral of complex cases (such as TSC, see

342 Supplementary materials). The shift towards more complex patients, including extratemporal and 
343 MRI negative cases, has been observed in centres around Europe (Baud et al. 2018), and this

344 might have been reflected in the cognitive performance of epilepsy surgery patients. Naturally,

345 we cannot exclude the effect of small sample size in certain aetiological groups with less

346 frequent pathologies. To summarize, the aetiological spectrum of epilepsy surgery candidates has

347 changed significantly in terms of the underlying aetiology (see Supplementary materials and

348 (Belohlavkova et al. 2019)) but the overall IQ/DQ scores remained similar.

349 Cognitive performance of children undergoing epilepsy surgery varies based on aetiology and

350 epileptic syndrome

351 Given the broad spectrum of epileptic syndromes and underlying aetiologies in the studied

352 population we hypothesised that these patients enter pre-surgical evaluation as distinct groups

353 with distinct cognitive performances. According to our analyses, patients with hemispheric

354 syndromes perform significantly lower in their IQ/DQ scores than their counterparts with

355 temporal or extratemporal epilepsy; however, they also have the greatest potential for post-

356 surgical increase in IQ/DQ scores, compared to patients with TLE or XTLE. These results are in

357 line with the results from previous studies showing that patients with hemimegalencephaly profit

358 from early epilepsy surgery (Bulteau et al. 2013; Honda et al. 2013). Considering the aetiological

359 spectrum of epilepsy surgery patients we hypothesised that patients with developmental

360 structural lesions, such as TSC, MCD or long-term epilepsy-associated tumours differ from those

361 with acquired lesions (e.g. inflammation, glial scar, etc.), but our data showed the opposite. It is

362 rather the specific aetiology itself and the extent of involvement (temporal vs. extratemporal vs.

363 hemispheric epilepsy) that distinguish these patients from each other. Patients with benign

364 tumours achieve significantly better pre- and post-surgical IQ/DQ scores than those with other

365 developmental abnormalities, e.g. TSC or MCD. Given their tendency to reach favourable 
366 seizure outcome, in addition to good cognitive outcome, they represent a group that might

367 benefit from early referral to epilepsy surgery (Ramantani et al. 2014). Patients with TSC, on the

368 other hand, tend to suffer from developmental delay spanning from mild cognitive impairment to

369 profound intellectual disability in $14 \%$ to $31 \%$ respectively (Joinson et al. 2003). Despite on-

370 going discussions about the pathogenesis of cognitive impairment in TSC (Curatolo et al. 2016;

371 Chu-Shore et al. 2010), most authors agree that adequate seizure control, achieved by

372 antiepileptic medication or epilepsy surgery, in TSC patients leads to improved cognitive

373 outcomes (Arya et al. 2015; Chu-Shore et al. 2010).

374 In histopathological FCD subgroups, we observed a tendency towards better cognitive

375 performance in FCD type III, with the most significant difference in relation to FCD type I.

376 Lower IQ/DQ scores and worse outcomes of epilepsy surgery have been repeatedly observed in

377 patients with FCD type I in contrast to FCD type II (Krsek et al. 2008; Krsek et al. 2009). FCD

378 type III has only recently been distinguished as a separate category of FCD (Blumcke et al.

379 2011); therefore, it is difficult to compare the results of more and less recent studies.

380 Nevertheless, FCD type III from its definition associates with other pathologies, e.g.

381 hippocampal sclerosis (FCD IIIa) or brain tumour (FDC type IIIb), and patients with these

382 pathologies achieved higher IQ/DQ scores which also explains the observed results. We

383 observed lower pre- and post-surgical IQ/DQ in the period post-2011 in the group of FCD type I;

384 this might be a result of the rather small sample size $(n=15)$. Another plausible explanation is

385 that we tend to accept patients with more severe epilepsy and its related adverse cognitive

386 sequelae in the epilepsy surgery program. It remains to be discovered whether and to what extent

387 molecular genetic changes in patients with FCD influence their prognosis in terms of both

388 seizure and cognitive outcome (Baldassari et al. 2018; Benova \& Jacques 2018). 
Multiple factors influence cognitive performance in children undergoing epilepsy surgery

390

391

392

393

394

395

396

397

398

399

400

401

402

403

404

405

406

407

408

409

410

In the entire patient cohort we have identified multiple factors that might affect their cognitive

performance. Factors associated with severe epilepsy, including early age at onset, frequent

seizures, occurrence of infantile spasms and status epilepticus seemed to be associated with

lower pre-surgical IQ/DQ scores. Given that patients suffering from infantile spasms tend to

improve in their cognitive skills after successful epilepsy surgery (Asarnow et al. 1997) low

IQ/DQ scores should not preclude timely referral for epilepsy surgery. In fact, patients with low

pre-surgical IQ/DQ scores do benefit from epilepsy surgery even though their chance to achieve seizure freedom decreases with lower IQ/DQ scores (Malmgren et al. 2008). Overall, our data

support the original concept of epileptic encephalopathy wherein epileptic activity itself

contributes to cognitive decline (Berg et al. 2010). Therefore, in light of our findings supported

by multiple studies advocating for epilepsy surgery as a treatment of choice in drug resistant

focal epilepsy, we conclude that epilepsy surgery leads to favourable seizure and cognitive

outcomes in carefully selected patients (Dwivedi et al. 2017; Harvey et al. 2008; Holthausen et

al. 2013; Ryvlin et al. 2014; Van Schooneveld \& Braun 2013).

To summarize, patients with varying underlying aetiologies tend to differ in their pre- and postsurgical IQ/DQ scores but not in their IQ/DQ change, we therefore suggest that despite the differences in pre-surgical cognitive performance, patients with various underlying aetiologies

may all benefit from epilepsy surgery. These findings are also supported by the regression curve equation that shows that patients with lower pre-surgical IQ/DQ tend to profit most from epilepsy surgery. Understandably, they would still achieve significantly lower post-surgical IQ/DQ scores as post-surgical IQ/DQ scores correlate strongly with pre-surgical IQ/DQ. 
411 Admittedly, our study displays certain limitations, the greatest being the short follow-up period

412 of one year. Indeed, some authors show that only longitudinal studies over lengthy study periods

413 provide solid evidence of cognitive improvement after epilepsy surgery, associated with

414 cessation of antiepileptic medication (Sibilia et al. 2017; Skirrow et al. 2011). On the other hand,

415 the length of follow-up period in previously published studies spans from few months to many

416 years (Moosa \& Wyllie 2017; Van Schooneveld \& Braun 2013). Most recently published studies

417 do provide evidence of cognitive improvement or improved cognitive trajectory over longer time

418 periods; however, these studies have other limitations, e.g. smaller sample size or they fail to

419 discern between different aetiologies (Puka et al. 2017; Sibilia et al. 2017). Most importantly

420 however, in our study, we aimed primarily to compare trends in cognitive performance between

421 the periods of developing vs. established epilepsy surgery centre and to analyse whether epilepsy

422 surgery candidates differ in their cognitive performance based on underlying aetiology and

423 epileptic syndrome. Further longitudinal studies are needed to provide unequivocal evidence that

424 paediatric epilepsy surgery can reverse the course of epileptic encephalopathy and lead to

425 cognitive recovery or at least prevent further cognitive decline.

426 Due to repeated neuropsychological testing, we could not have completely eliminated a possible

427 effect of repeated testing. Although some authors claim that the practice effect in paediatric

428 population is not significant (Westerveld et al. 2000), others believe it may interfere with the

429 correct evaluation of cognitive outcomes in paediatric epilepsy surgery (Sherman et al. 2003). In

430 addition, given the age diversity of our population, our study faced the issue of comparability of

431 various age-adjusted versions of IQ/DQ tests. We believe both of these issued will be addressed

432 in future studies in which we aim to validate our findings over a longer follow-up period with

433 wider intervals between repeated testing on a more homogenous age-groups of children. 
434 Despite rather large sample size, some numbers of patients in individual subgroups remain small 435 and this precluded some further analyses, e.g. the effect of complications of epilepsy surgery on

436 post-surgical IQ/DQ score. However this also shows that overall, major complications of

437 epilepsy surgery occur rarely in our centre as well as others (Bjellvi et al. 2015). Our study also

438 lacked data on socioeconomic status of patients' families that might have affected IQ/DQ

439 change; in fact, parents' education seems to independently contribute to IQ/DQ increase after

440 epilepsy surgery (Meekes et al. 2015), while income and residence do not have significant effect

441 (Puka et al. 2016). Therefore, the effect of families' socioeconomic status on cognitive

442 performance in children undergoing epilepsy surgery warrants further consideration, both in

443 research and in clinical practice.

444 Another significant limitation concerns the effect of antiepileptic drugs (AED) on post-surgical

445 cognitive outcome. It has been shown that AED withdrawal leads to improved cognitive skills in

446 children undergoing epilepsy surgery, and that IQ scores tend to increase with decreasing

447 number of AED (Boshuisen et al. 2015b). Given the short period of post-operative follow-up

448 period we were unable to assess the effect of AED withdrawal as the vast majority of patients

449 remain on pre-surgical dose of AED at least one year after epilepsy surgery. Accumulating

450 evidence advocates for early AED withdrawal (Boshuisen et al. 2012; Braun \& Schmidt 2014),

451 and a randomized control trial on the effect of early vs. late AED withdrawal on cognitive

452 outcomes is ongoing (Boshuisen et al. 2015a).

453

454 Conclusion

455 Epilepsy surgery may lead to improvement of cognitive performance in patients with drug

456 resistant focal epilepsy, especially in those with lower pre-surgical IQ/DQ scores; this warrants 
457

458

459

460

461

462

463

464

465

466

467

468

469

470

471

472

473

474

475

476

477

478

479

480

481

482

483

484

485

486

487

488

489

490

491

early referral to epilepsy surgery centres. Patients with varying aetiologies and epileptic

syndromes enter epilepsy surgery evaluation with distinct cognitive performances and diverse

potential for recovery and should be counselled accordingly. In future, longitudinal studies with

lengthier follow-up periods and inclusion of novel genetic findings may elucidate mechanisms

behind cognitive dysfunction in patients with focal drug resistant epilepsy and contribute to more

precise prognosis and counselling.

\section{Acknowledgements}

The authors would like to thank their respective clinical teams taking care of patients involved

and to the patients and their families themselves for their support and collaboration on the study.

\section{References}

Arya R, Tenney JR, Horn PS, Greiner HM, Holland KD, Leach JL, Gelfand MJ, Rozhkov L, Fujiwara H, Rose DF, Franz DN, and Mangano FT. 2015. Long-term outcomes of resective epilepsy surgery after invasive presurgical evaluation in children with tuberous sclerosis complex and bilateral multiple lesions. J Neurosurg Pediatr 15:26-33. 10.3171/2014.10.peds 14107

Asarnow RF, LoPresti C, Guthrie D, Elliott T, Cynn V, Shields WD, Shewmon DA, Sankar R, and Peacock WJ. 1997. Developmental outcomes in children receiving resection surgery for medically intractable infantile spasms. Dev Med Child Neurol 39:430-440.

Baldassari S, Picard F, Verbeek NE, van Kempen M, Brilstra EH, Lesca G, Conti V, Guerrini R, Bisulli F, Licchetta L, Pippucci T, Tinuper P, Hirsch E, de Saint Martin A, Chelly J, Rudolf G, Chipaux M, Ferrand-Sorbets S, Dorfmuller G, Sisodiya S, Balestrini S, Schoeler N, Hernandez-Hernandez L, Krithika S, Oegema R, Hagebeuk E, Gunning B, Deckers C, Berghuis B, Wegner I, Niks E, Jansen FE, Braun K, de Jong D, Rubboli G, Talvik I, Sander V, Uldall P, Jacquemont ML, Nava C, Leguern E, Julia S, Gambardella A, d'Orsi G, Crichiutti G, Faivre L, Darmency V, Benova B, Krsek P, Biraben A, Lebre AS, Jennesson M, Sattar S, Marchal C, Nordli DR, Jr., Lindstrom K, Striano P, Lomax LB, Kiss C, Bartolomei F, Lepine AF, Schoonjans AS, Stouffs K, Jansen A, Panagiotakaki E, Ricard-Mousnier B, Thevenon J, de Bellescize J, Catenoix H, Dorn T, Zenker M, Muller-Schluter K, Brandt C, Krey I, Polster T, Wolff M, Balci M, Rostasy K, Achaz G, Zacher P, Becher T, Cloppenborg T, Yuskaitis CJ, Weckhuysen S, Poduri A, Lemke JR, Moller RS, Baulac S, and Baulac S. 2018. The landscape of epilepsy-related GATOR1 variants. Genet Med. 10.1038/s41436-018-0060-2 
492

493

494

495

496

497

498

499

500

501

502

503

504

505

506

507

508

509

510

511

512

513

514

515

516

517

518

519

520

521

522

523

524

525

526

527

528

529

530

531

532

533

534

535

536

537

Baud MO, Perneger T, Racz A, Pensel MC, Elger C, Rydenhag B, Malmgren K, Cross JH, McKenna G, Tisdall M, Lamberink HJ, Rheims S, Ryvlin P, Isnard J, Mauguiere F, Arzimanoglou A, Akkol S, Deniz K, Ozkara C, Lossius M, Rektor I, Kalviainen R, Vanhatalo LM, Dimova P, Minkin K, Staack AM, Steinhoff BJ, Kalina A, Krsek P, Marusic P, Jordan Z, Fabo D, Carrette E, Boon P, Rocka S, Mameniskiene R, Vulliemoz S, Pittau F, Braun KPJ, and Seeck M. 2018. European trends in epilepsy surgery. Neurology 91:e96-e106. 10.1212/wnl.0000000000005776

Bayley N. 1993. Bayley scales of infant development: Manual: Psychological Corporation. Belohlavkova A, Jezdik P, Jahodova A, Kudr M, Benova B, Maulisova A, Liby P, Vaculik M, Lesko R, Kyncl M, Zamecnik J, Tichy M, Komarek V, and Krsek P. 2019. Evolution of pediatric epilepsy surgery program over 2000-2017: Improvement of care? Eur J Paediatr Neurol 23:456-465. 10.1016/j.ejpn.2019.04.002

Benova B, and Jacques TS. 2018. Genotype-phenotype correlations in focal malformations of cortical development: a pathway to integrated pathological diagnosis in epilepsy surgery. Brain Pathol. 10.1111/bpa.12686

Berg AT, Berkovic SF, Brodie MJ, Buchhalter J, Cross JH, van Emde Boas W, Engel J, French J, Glauser TA, Mathern GW, Moshe SL, Nordli D, Plouin P, and Scheffer IE. 2010. Revised terminology and concepts for organization of seizures and epilepsies: report of the ILAE Commission on Classification and Terminology, 2005-2009. Epilepsia 51:676685. 10.1111/j.1528-1167.2010.02522.x

Bjellvi J, Flink R, Rydenhag B, and Malmgren K. 2015. Complications of epilepsy surgery in Sweden 1996-2010: a prospective, population-based study. J Neurosurg 122:519-525. 10.3171/2014.9.JNS132679

Blumcke I, Thom M, Aronica E, Armstrong DD, Vinters HV, Palmini A, Jacques TS, Avanzini G, Barkovich AJ, Battaglia G, Becker A, Cepeda C, Cendes F, Colombo N, Crino P, Cross JH, Delalande O, Dubeau F, Duncan J, Guerrini R, Kahane P, Mathern G, Najm I, Ozkara C, Raybaud C, Represa A, Roper SN, Salamon N, Schulze-Bonhage A, Tassi L, Vezzani A, and Spreafico R. 2011. The clinicopathologic spectrum of focal cortical dysplasias: a consensus classification proposed by an ad hoc Task Force of the ILAE Diagnostic Methods Commission. Epilepsia 52:158-174. 10.1111/j.15281167.2010.02777.x

Boshuisen K, Arzimanoglou A, Cross JH, Uiterwaal CS, Polster T, van Nieuwenhuizen O, and Braun KP. 2012. Timing of antiepileptic drug withdrawal and long-term seizure outcome after paediatric epilepsy surgery (TimeToStop): a retrospective observational study. Lancet Neurol 11:784-791. 10.1016/s1474-4422(12)70165-5

Boshuisen K, Lamberink HJ, van Schooneveld MM, Cross JH, Arzimanoglou A, van der Tweel I, Geleijns K, Uiterwaal CS, and Braun KP. 2015a. Cognitive consequences of early versus late antiepileptic drug withdrawal after pediatric epilepsy surgery, the TimeToStop (TTS) trial: study protocol for a randomized controlled trial. Trials 16:482. 10.1186/s13063-015-0989-2

Boshuisen K, van Schooneveld MM, Uiterwaal CS, Cross JH, Harrison S, Polster T, Daehn M, Djimjadi S, Yalnizoglu D, Turanli G, Sassen R, Hoppe C, Kuczaty S, Barba C, Kahane P, Schubert-Bast S, Reuner G, Bast T, Strobl K, Mayer H, de Saint-Martin A, Seegmuller C, Laurent A, Arzimanoglou A, and Braun KP. 2015b. Intelligence quotient improves after antiepileptic drug withdrawal following pediatric epilepsy surgery. Ann Neurol 78:104114. 10.1002/ana.24427 
538

539

540

541

542

543

544

545

546

547

548

549

550

551

552

553

554

555

556

557

558

559

560

561

562

563

564

565

566

567

568

569

570

571

572

573

574

575

576

577

578

579

580

581
Braun KP, and Schmidt D. 2014. Stopping antiepileptic drugs in seizure-free patients. Curr Opin Neurol 27:219-226. 10.1097/wco.0000000000000075

Bulteau C, Otsuki T, and Delalande O. 2013. Epilepsy surgery for hemispheric syndromes in infants: hemimegalencepahly and hemispheric cortical dysplasia. Brain Dev 35:742-747. 10.1016/j.braindev.2013.05.004

Curatolo P, Aronica E, Jansen A, Jansen F, Kotulska K, Lagae L, Moavero R, and Jozwiak S. 2016. Early onset epileptic encephalopathy or genetically determined encephalopathy with early onset epilepsy? Lessons learned from TSC. European journal of paediatric neurology : EJPN : official journal of the European Paediatric Neurology Society 20:203-211. 10.1016/j.ejpn.2015.12.005

Dwivedi R, Ramanujam B, Chandra PS, Sapra S, Gulati S, Kalaivani M, Garg A, Bal CS, Tripathi M, Dwivedi SN, Sagar R, Sarkar C, and Tripathi M. 2017. Surgery for DrugResistant Epilepsy in Children. N Engl J Med 377:1639-1647. 10.1056/NEJMoa1615335

Freitag H, and Tuxhorn I. 2005. Cognitive function in preschool children after epilepsy surgery: rationale for early intervention. Epilepsia 46:561-567. 10.1111/j.00139580.2005.03504.x

Harvey AS, Cross JH, Shinnar S, Mathern GW, and Taskforce IPESS. 2008. Defining the spectrum of international practice in pediatric epilepsy surgery patients. Epilepsia 49:146-155. 10.1111/j.1528-1167.2007.01421.x

Hemb M, Velasco TR, Parnes MS, Wu JY, Lerner JT, Matsumoto JH, Yudovin S, Shields WD, Sankar R, Salamon N, Vinters HV, and Mathern GW. 2010. Improved outcomes in pediatric epilepsy surgery: the UCLA experience, 1986-2008. Neurology 74:1768-1775. 10.1212/WNL.0b013e3181e0f17a

Holthausen H, Pieper T, and Kudernatsch M. 2013. Towards early diagnosis and treatment to save children from catastrophic epilepsy -- focus on epilepsy surgery. Brain Dev 35:730741. 10.1016/j.braindev.2013.05.003

Honda R, Kaido T, Sugai K, Takahashi A, Kaneko Y, Nakagwa E, Sasaki M, and Otsuki T. 2013. Long-term developmental outcome after early hemispherotomy for hemimegalencephaly in infants with epileptic encephalopathy. Epilepsy Behav 29:30-35. 10.1016/j.yebeh.2013.06.006

Chu-Shore CJ, Major P, Camposano S, Muzykewicz D, and Thiele EA. 2010. The natural history of epilepsy in tuberous sclerosis complex. Epilepsia 51:1236-1241. 10.1111/j.15281167.2009.02474.x

Joinson C, O'Callaghan FJ, Osborne JP, Martyn C, Harris T, and Bolton PF. 2003. Learning disability and epilepsy in an epidemiological sample of individuals with tuberous sclerosis complex. Psychol Med 33:335-344.

Krsek P, Maton B, Korman B, Pacheco-Jacome E, Jayakar P, Dunoyer C, Rey G, Morrison G, Ragheb J, Vinters HV, Resnick T, and Duchowny M. 2008. Different features of histopathological subtypes of pediatric focal cortical dysplasia. Ann Neurol 63:758-769. 10.1002/ana. 21398

Krsek P, Pieper T, Karlmeier A, Hildebrandt M, Kolodziejczyk D, Winkler P, Pauli E, Blumcke I, and Holthausen H. 2009. Different presurgical characteristics and seizure outcomes in children with focal cortical dysplasia type I or II. Epilepsia 50:125-137. 10.1111/j.15281167.2008.01682.x 
582

583

584

585

586

587

588

589

590

591

592

593

594

595

596

597

598

599

600

601

602

603

604

605

606

607

608

609

610

611

612

613

614

615

616

617

618

619

620

621

622

623

624

625

626

627

Lamberink HJ, Boshuisen K, van Rijen PC, Gosselaar PH, and Braun KP. 2015. Changing profiles of pediatric epilepsy surgery candidates over time: A nationwide single-center experience from 1990 to 2011. Epilepsia 56:717-725. 10.1111/epi.12974

Lee YJ, Lee JS, Kang HC, Kim DS, Shim KW, Eom S, and Kim HD. 2014. Outcomes of epilepsy surgery in childhood-onset epileptic encephalopathy. Brain Dev 36:496-504. 10.1016/j.braindev.2013.06.010

Loddenkemper T, Holland KD, Stanford LD, Kotagal P, Bingaman W, and Wyllie E. 2007. Developmental outcome after epilepsy surgery in infancy. Pediatrics 119:930-935. 10.1542/peds.2006-2530

Malmgren K, Olsson I, Engman E, Flink R, and Rydenhag B. 2008. Seizure outcome after resective epilepsy surgery in patients with low IQ. Brain 131:535-542. 10.1093/brain/awm296

Meekes J, van Schooneveld MM, Braams OB, Jennekens-Schinkel A, van Rijen PC, Hendriks MP, Braun KP, and van Nieuwenhuizen O. 2015. Parental education predicts change in intelligence quotient after childhood epilepsy surgery. Epilepsia 56:599-607. 10.1111/epi.12938

Moosa ANV, and Wyllie E. 2017. Cognitive Outcome After Epilepsy Surgery in Children. Semin Pediatr Neurol 24:331-339. 10.1016/j.spen.2017.10.010

Puka K, Rubinger L, Chan C, Smith ML, and Widjaja E. 2016. Predictors of intellectual functioning after epilepsy surgery in childhood: The role of socioeconomic status. Epilepsy Behav 62:35-39. 10.1016/j.yebeh.2016.06.023

Puka K, Tavares TP, and Smith ML. 2017. Development of intelligence 4 to 11 years after paediatric epilepsy surgery. J Neuropsychol 11:161-173. 10.1111/jnp.12081

Ramantani G, Kadish NE, Anastasopoulos C, Brandt A, Wagner K, Strobl K, Mayer H, Schubert-Bast S, Stathi A, Korinthenberg R, Feuerstein TJ, Mader I, van Velthoven V, Zentner J, Schulze-Bonhage A, and Bast T. 2014. Epilepsy surgery for glioneuronal tumors in childhood: avoid loss of time. Neurosurgery 74:648-657; discussion 657. 10.1227/neu.0000000000000327

Ryvlin P, Cross JH, and Rheims S. 2014. Epilepsy surgery in children and adults. Lancet Neurol 13:1114-1126. 10.1016/s1474-4422(14)70156-5

Sherman E, Slick DJ, Connolly MB, Steinbok P, Martin R, Strauss E, Chelune GJ, and Farrell K. 2003. Reexamining the effects of epilepsy surgery on IQ in children: use of regressionbased change scores. J Int Neuropsychol Soc 9:879-886.

Sibilia V, Barba C, Metitieri T, Michelini G, Giordano F, Genitori L, and Guerrini R. 2017. Cognitive outcome after epilepsy surgery in children: A controlled longitudinal study. Epilepsy Behav 73:23-30. 10.1016/j.yebeh.2017.03.001

Skirrow C, Cross JH, Cormack F, Harkness W, Vargha-Khadem F, and Baldeweg T. 2011. Long-term intellectual outcome after temporal lobe surgery in childhood. Neurology 76:1330-1337. 10.1212/WNL.0b013e31821527f0

Thorndike RL, Hagen, E. P., Sattler, J. M. 1986. The Stanford-Binet intelligence scale, fourth edition: Riverside Pub. Co. Chicago, IL

Van Schooneveld MM, and Braun KP. 2013. Cognitive outcome after epilepsy surgery in children. Brain Dev 35:721-729. 10.1016/j.braindev.2013.01.011

Viggedal G, Kristjansdottir R, Olsson I, Rydenhag B, and Uvebrant P. 2012. Cognitive development from two to ten years after pediatric epilepsy surgery. Epilepsy Behav 25:28. 10.1016/j.yebeh.2012.06.010 
628 Viggedal G, Olsson I, Carlsson G, Rydenhag B, and Uvebrant P. 2013. Intelligence two years 629 after epilepsy surgery in children. Epilepsy Behav 29:565-570.

$630 \quad 10.1016 /$ j.yebeh.2013.10.012

631 Wechsler D. 2002. Wechslerova inteligenční škála pro děti : WISC - III: Praha : Testcentrum. 632 Wechsler D. 2010. WAIS-III : Wechslerova inteligenční škála pro dospělé: Praha : Testcentrum. 633 Westerveld M, Sass KJ, Chelune GJ, Hermann BP, Barr WB, Loring DW, Strauss E, Trenerry 634 MR, Perrine K, and Spencer DD. 2000. Temporal lobectomy in children: cognitive 635 outcome. J Neurosurg 92:24-30. 10.3171/jns.2000.92.1.0024

636

637 


\section{Figure 1}

\section{Result of the regression analysis.}

The figure depicts correlation of pre- and post-surgical IQ/DQ scores, along with the respective confidence intervals (dashed line) in the whole dataset, in children above and below 6 and 12 years of age. The respective regression equations are listed too.
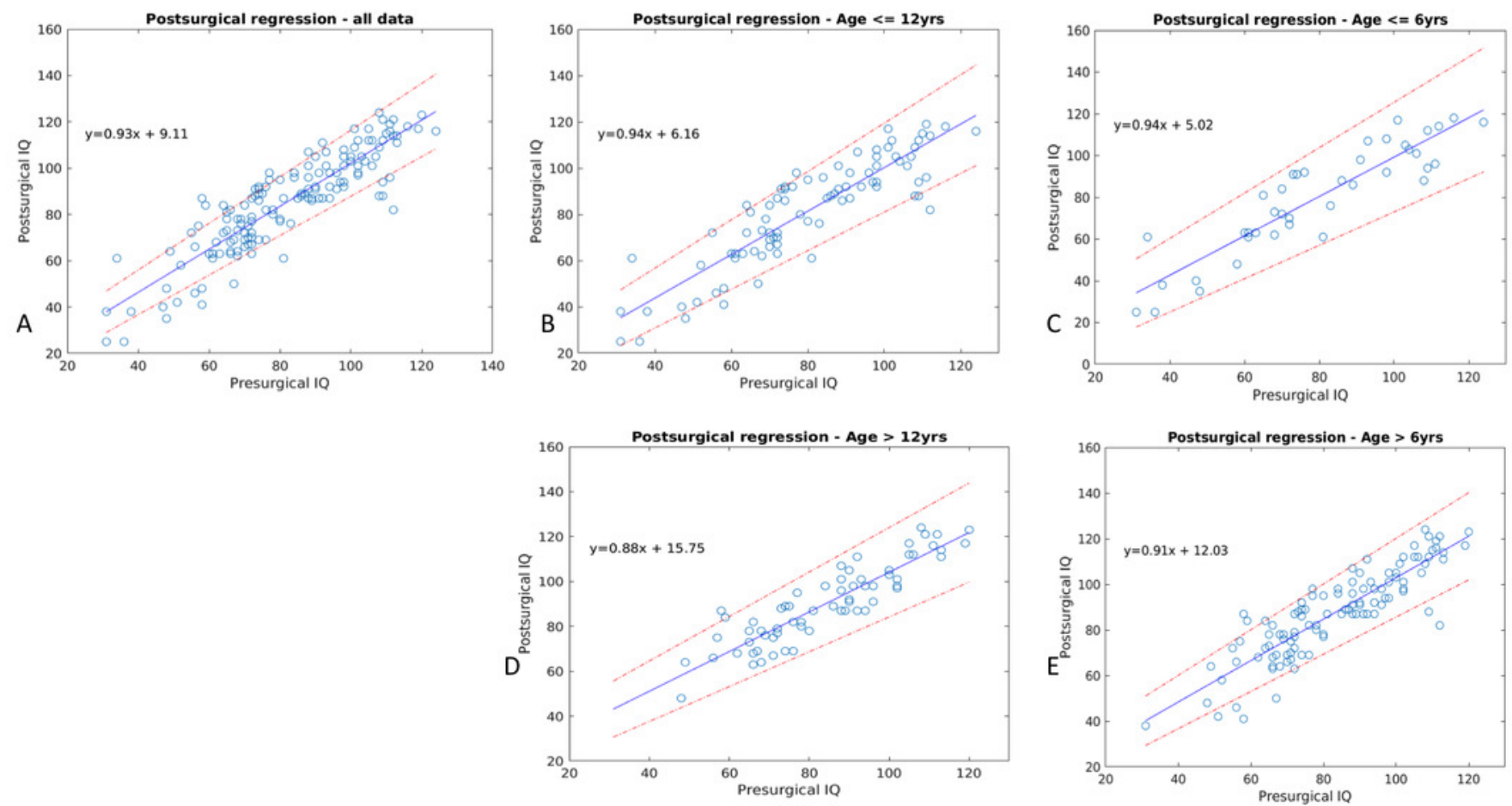
Figure 2

Pre-and post-surgical IQ-DQ and IQ/DQ change in distinct groups of patients according to epilepsy-related features.

FCD: focal cortical dysplasia, MCD: malformations of cortical development, TSC: tuberous sclerosis complex, TLE: temporal lobe epilepsy, XTLE: extratemporal lobe epilepsy, HEMI: hemispheric epilepsy.
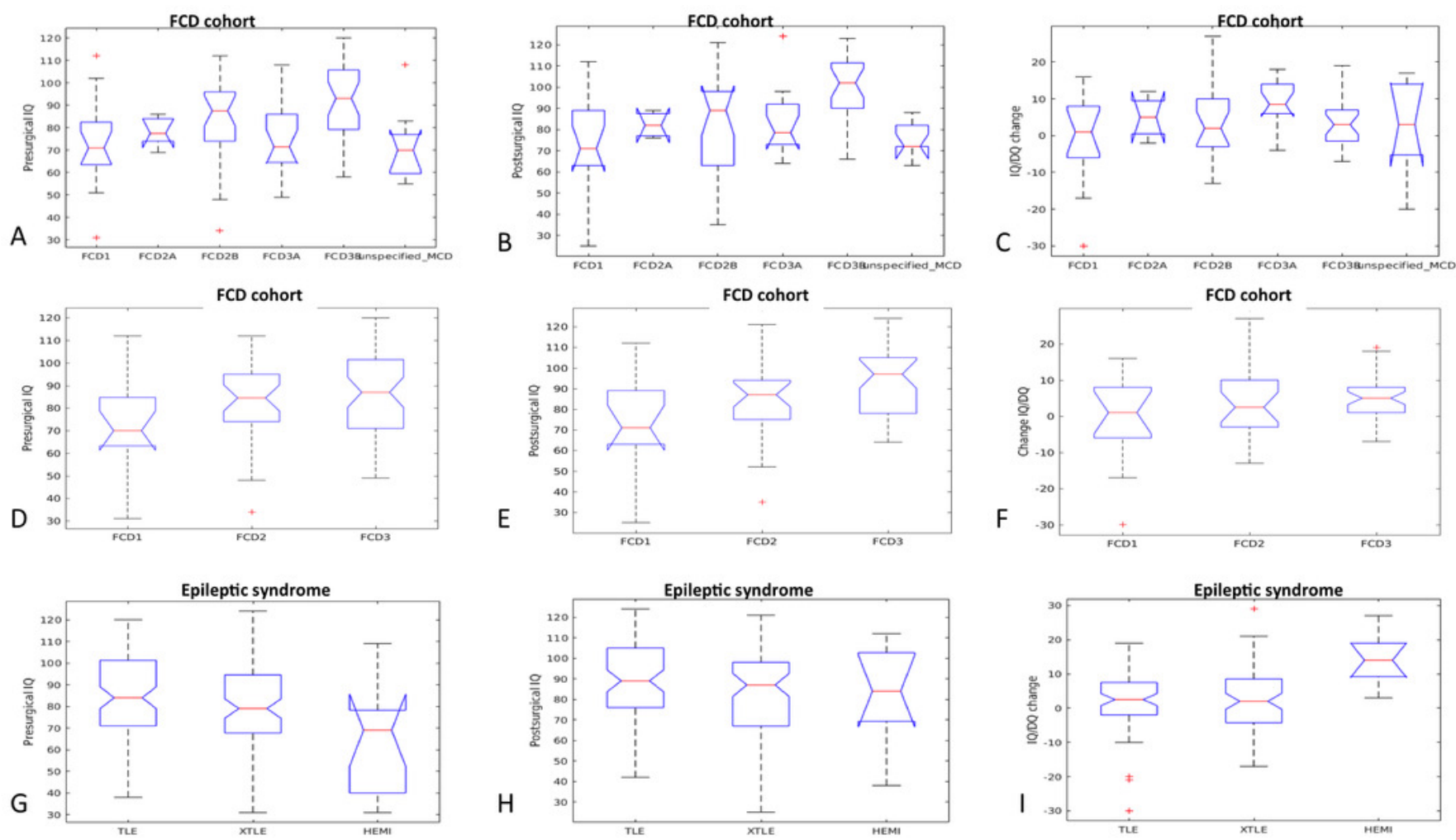


\section{Table $\mathbf{1}$ (on next page)}

Demographic features of patients included in the study.

The table shows demographic features of patients included in the study. TLE: temporal lobe epilepsy, XTLE: extratemporal lobe epilepsy, HEMI: hemispheric epilepsy, FCD: focal cortical dysplasia, MCD: malformations of cortical development, TSC: tuberous sclerosis complex, FBTCS: focal to bilateral tonic clonic seizure, LEAT: long-term epilepsy-associated tumours 


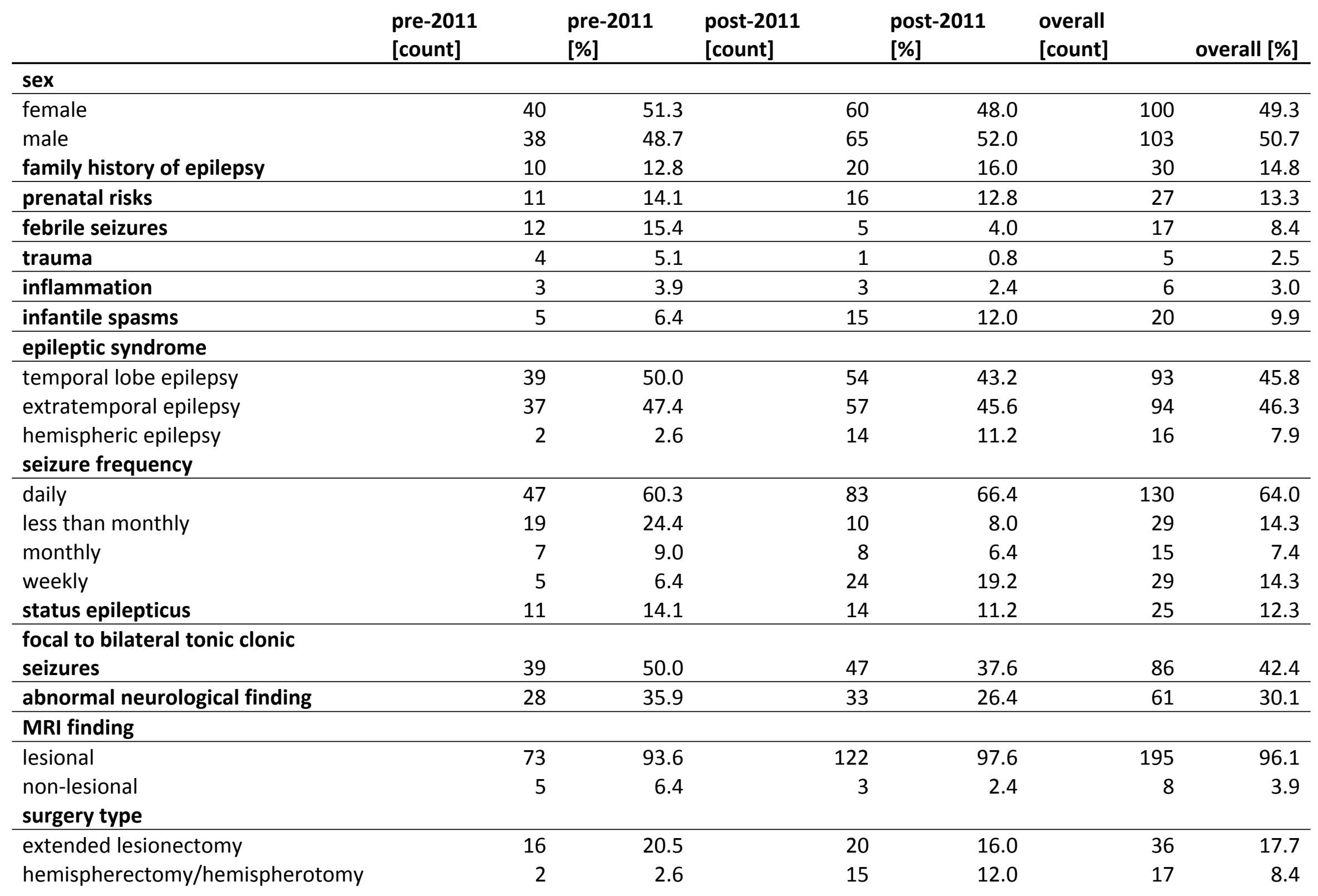




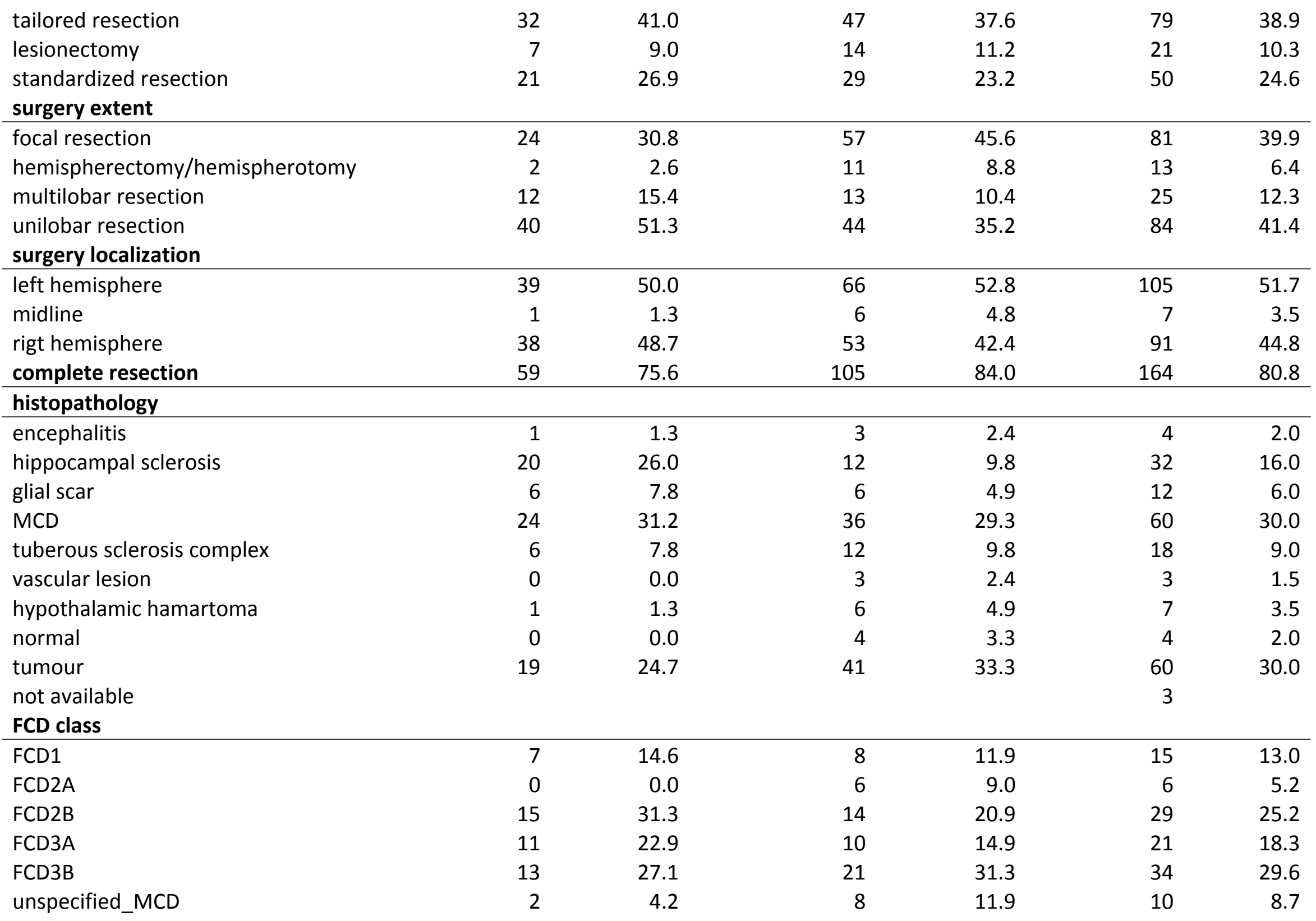




\begin{tabular}{|c|c|c|c|c|c|c|}
\hline early post-operative seizures & 8 & 10.4 & 17 & 13.6 & 25 & 12.4 \\
\hline \multicolumn{7}{|l|}{ complication type } \\
\hline minor & 6 & 60.0 & 10 & 62.5 & 16 & 61.5 \\
\hline FCD1 & 7 & 15.2 & 8 & 13.6 & 15 & 14.3 \\
\hline FCD2 & 15 & 32.6 & 20 & 33.9 & 35 & 33.3 \\
\hline \multicolumn{7}{|l|}{ epoch } \\
\hline before 2011 & 78 & 100.0 & 0 & 0.0 & 78 & 38.4 \\
\hline after 2011 & 0 & 0.0 & 125 & 100.0 & 125 & 61.6 \\
\hline \multicolumn{7}{|l|}{1 year follow-up period } \\
\hline seizure-free & 66 & 86.8 & 106 & 89.8 & 172 & 88.7 \\
\hline seizure reduction $<50 \%$ & 6 & 7.9 & 6 & 5.1 & 12 & 6.2 \\
\hline
\end{tabular}




\section{Table 2 (on next page)}

Table showing results of univariate testing of categorical variables.

The table shows categorical variables associated with pre- $(A)$ and post-surgical IQ/DQ (B) and IQ/DQ change (C). Cl: confidence interval, SE: standard error, SD: standard deviation, FCD: focal cortical dysplasia, df: degrees of freedom 
A: Determinants of pre-surgical IQ/DQ $(n=191)$

\begin{tabular}{|l|r|l|r|r|r|r|}
\hline & $\begin{array}{l}\text { median } \\
\text { difference } \\
\text { variable name }\end{array}$ & $\begin{array}{l}\text { mean } \\
\text { difference } \\
(\mathbf{9 5 \%} \mathbf{~ C l})\end{array}$ & $\begin{array}{l}\text { p- } \\
\text { value }\end{array}$ & effect size & Fstat & df \\
\hline prenatal risks & $8(0,17)$ & $9.0(1,17)$ & 0,031 & 0,019 & 4,722 & 189 \\
\hline infantile spasms & $20(9,30)$ & $19.1(10,28)$ & $<0.001$ & 0,070 & 15,305 & 189 \\
\hline epileptic syndrome & & & 0,001 & 0,058 & 6,832 & 188 \\
\hline seizure frequency & & & 0,035 & 0,029 & 2,921 & 187 \\
\hline status epilepticus & $11(2,20)$ & $10.7(2,19)$ & 0,018 & 0,024 & 5,725 & 189 \\
\hline abnormal neurological finding & $18(13,25)$ & $18.5(13,24)$ & $<0.001$ & 0,171 & 40,231 & 189 \\
\hline histopathology & & & $<0.001$ & 0,184 & 6,281 & 189 \\
\hline FCD class & & & 0,001 & 0,145 & 4,573 & 189 \\
\hline B: Determinants of post-surg & & & & &
\end{tabular}

\section{B: Determinants of post-surgical IQ/DQ $(n=156)$}

\begin{tabular}{|l|l|l|r|r|r|r|}
\hline & $\begin{array}{l}\text { median } \\
\text { difference } \\
(\mathbf{9 5 \%} \mathbf{~ C l})\end{array}$ & $\begin{array}{l}\text { mean } \\
\text { difference } \\
(\mathbf{9 5 \%} \mathbf{C l})\end{array}$ & $\begin{array}{l}\text { p- } \\
\text { value }\end{array}$ & effect size & Fstat & df \\
\hline infantile spasms & $26(13,39)$ & $25.6(15,36)$ & $<0.001$ & 0,121 & 22,383 & 154 \\
\hline seizure frequency & & & 0,014 & 0,048 & 3,631 & 152 \\
\hline status epilepticus & $15(5,25)$ & $14.8(4,26)$ & 0,010 & 0,036 & 6,855 & 154 \\
\hline abnormal neurological finding & $17(9,25)$ & $16.6(10,23)$ & $<0.001$ & 0,119 & 21,928 & 154 \\
\hline surgery type & & & $<0.001$ & 0,109 & 5,724 & 151 \\
\hline surgery extent & & & $<0.001$ & 0,118 & 7,902 & 152 \\
\hline complete resection & & $-13.3(-21,-6)$ & 0,001 & 0,062 & 11,268 & 154 \\
\hline histopathology & & & $<0.001$ & 0,243 & 7,129 & 145 \\
\hline FCD class & & & 0,001 & 0,177 & 4,572 & 78 \\
\hline FCD1 & & & 0,008 & 0,072 & 7,443 & 82 \\
\hline FCD3B & & & $<0.001$ & 0,178 & 19,009 & 82 \\
\hline 1 year follow-up period & & & 0,035 & 0,037 & 2,953 & 150 \\
\hline age class12 & & $-7.5(-14,-1)$ & 0,027 & 0,025 & 4,956 & 154 \\
\hline age class6 & $-6(-12,0)$ & $-8.7(-16,-2)$ & 0,024 & 0,026 & 5,167 & 154 \\
\hline C: Determinants & & & &
\end{tabular}

C: Determinants of IQ/DQ change $(n=154)$

\begin{tabular}{|l|l|l|r|r|r|r|}
\hline & $\begin{array}{l}\text { median } \\
\text { difference } \\
\mathbf{( 9 5 \% ~ C l )}\end{array}$ & $\begin{array}{l}\text { mean } \\
\text { difference } \\
(\mathbf{9 5 \%} \mathbf{C l})\end{array}$ & \multicolumn{1}{l}{$\begin{array}{l}\text { p- } \\
\text { value }\end{array}$} & effect size & Fstat & df \\
\hline epileptic syndrome & & & 0,002 & 0,069 & 6,635 & 151 \\
\hline surgery type & & & 0,025 & 0,046 & 2,863 & 149 \\
\hline surgery extent & & & 0,011 & 0,052 & 3,822 & 150 \\
\hline FCD1 & & & 0,047 & 0,037 & 4,080 & 80 \\
\hline FCD3A & & & 0,022 & 0,052 & 5,430 & 80 \\
\hline age class12 & & $-4.6(-7,-2)$ & 0,004 & 0,048 & 8,795 & 152 \\
\hline age class6 & $-4(-7,-2)$ & $-4.0(-7,-1)$ & 0,027 & 0,025 & 4,961 & 152 \\
\hline
\end{tabular}




\section{Table 3 (on next page)}

Table showing results of univariate testing of continuous variables.

The table shows continuous variables associated with pre- (A) and post-surgical IQ/DQ (B) and IQ/DQ change (C). SE: standard error, dfe: degrees of freedom for error, sse: sum of squares for error, dfr: degrees of freedom for regression, ssr: sum of squares for regression 


\begin{tabular}{|c|c|c|c|}
\hline \multicolumn{2}{|c|}{ A: Determinants of presurgical IQ/DQ $(n=191)$} & & \\
\hline \multicolumn{2}{|c|}{ Univariate Regression } & & \\
\hline Variable & age of first seizure & & \\
\hline intercept & 73.9 & & \\
\hline SE & 2 & & \\
\hline t statistics & 36.88 & & \\
\hline$p$ value & $<0.001$ & & \\
\hline beta 1 & 1.55 & & \\
\hline SE & 0.3 & & \\
\hline t statistics & 5.2 & & \\
\hline$p$ value & $<0.001$ & & \\
\hline dfe & 189 & & \\
\hline sse & 65805 & & \\
\hline dfr & 1 & & \\
\hline ssr & 9416 & & \\
\hline$f$ & 27.05 & & \\
\hline$p$ value & $<0.001$ & & \\
\hline r2 effect size & 0.13 & & \\
\hline \multicolumn{4}{|c|}{ B: Determinants of postsurgical IQ/DQ ( $n=156)$} \\
\hline \multicolumn{4}{|c|}{ Univariate Regression } \\
\hline Variable & age of first seizure & age at surgery & duration of epilepsy \\
\hline intercept & 75.6 & 77.87 & 90 \\
\hline SE & 2.3 & 3.56 & 2.65 \\
\hline t statistics & 33.05 & 21.86 & 33.9 \\
\hline$p$ value & $<0.001$ & $<0.001$ & $<0.001$ \\
\hline beta 1 & 1.99 & 0.7 & 0.8 \\
\hline
\end{tabular}




\begin{tabular}{|c|c|c|c|}
\hline SE & 0.35 & 0.3 & 0.36 \\
\hline t statistics & 5.78 & 2.38 & -2.3 \\
\hline$p$ value & $<0.001$ & 0.02 & 0.02 \\
\hline dfe & 154 & 154 & 154 \\
\hline sse & 57589 & 67579 & 67798 \\
\hline dfr & 1 & 1 & 1 \\
\hline ssr & 12474 & 2484 & 2264 \\
\hline$f$ & 33.36 & 5.66 & 5.14 \\
\hline$p$ value & $<0.001$ & 0.02 & 0.02 \\
\hline r2 effect size & 0.18 & 0.04 & 0.03 \\
\hline \multicolumn{3}{|c|}{ C: Determinants of IQ/DQ change $(n=154)$} & \\
\hline \multicolumn{3}{|c|}{ Univariate Regression } & \\
\hline Variable & age at surgery & duration of epilepsy & \\
\hline intercept & -0.4 & 2.19 & \\
\hline SE & 1.66 & 1.25 & \\
\hline t statistics & -0.24 & 1.75 & \\
\hline$p$ value & 0.81 & 0.08 & \\
\hline beta 1 & 0.36 & 0.21 & \\
\hline SE & 0.14 & 0.17 & \\
\hline t statistics & 2.58 & 1.23 & \\
\hline$p$ value & 0.01 & 0.22 & \\
\hline dfe & 152 & 152 & \\
\hline sse & 14157 & 14629 & \\
\hline dfr & 1 & 1 & \\
\hline ssr & 617.55 & 145.83 & \\
\hline$f$ & 6.63 & 2 & \\
\hline
\end{tabular}




\begin{tabular}{|l|r|r|}
\hline$p$ value & 0.01 & 0.22 \\
\hline r2 effect size & 0.04 & 0.01 \\
\hline
\end{tabular}

1 


\section{Table 4(on next page)}

Table showing results of multivariate testing.

The table shows the results and features of multiple regression based on the general linear model of pre(A), post-surgical IQ/DQ (B) and IQ/DQ change (C). SE: standard error; TLE: temporal lobe epilepsy, XTLE: extratemporal lobe epilepsy, HEMI: hemispheric epilepsy, FCD: focal cortical dysplasia, MCD: malformations of cortical development, TSC: tuberous sclerosis complex, FBTCS: focal to bilateral tonic clonic seizure, LEAT: long-term epilepsy-associated tumours. 


\begin{tabular}{|c|c|c|c|c|}
\hline \multicolumn{5}{|c|}{ A: Multiple regression based on the general linear model of pre-surgical IQ/DQ } \\
\hline Variable & Estimate & SE & t statistics & p value \\
\hline Intercept & 71.61 & 4.84 & 14.81 & $<0.001$ \\
\hline age at first seizure & 0.82 & 0.38 & 2.18 & 0.03 \\
\hline abnormal neurological finding & -20.08 & 5.03 & -3.99 & $<0.001$ \\
\hline FCD Ila & 6.95 & 7.33 & 0.95 & 0.35 \\
\hline FCD $\| b$ & 14.29 & 4.97 & 2.87 & 5 \\
\hline FCD IIla & 1.02 & 5.21 & 0.2 & 0.84 \\
\hline FCD IIIb & 14.72 & 4.79 & 3.07 & 3 \\
\hline unspecified MCD & 12.75 & 6.82 & 1.87 & 0.06 \\
\hline Model Characteristics & Value & & & \\
\hline observations & 106 & & & \\
\hline error degrees of freedom & 97 & & & \\
\hline estimated dispersion & 221 & & & \\
\hline F-statistic vs. constant model & 7.77 & & & \\
\hline$p$ value & $<0.001$ & & & \\
\hline r2 effect size & 0.32 & & & \\
\hline \multicolumn{5}{|c|}{ B: Multiple regression based on the general linear model of post-surgical IQ/DQ } \\
\hline Variable & Estimate & SE & t statistics & p value \\
\hline Intercept & 93.6 & 11.55 & 8.1 & $<0.001$ \\
\hline age at first seizure & 0.82 & 0.34 & 2.42 & 0.02 \\
\hline status epilepticus & -11.27 & 4.76 & -2.37 & 0.02 \\
\hline hemispherectomy/hemispherotomy & -12.59 & 7.74 & -1.63 & 0.11 \\
\hline multilobar resection & -18.41 & 4.63 & -3.98 & $<0.001$ \\
\hline unilobar resection & -9.06 & 3.51 & -2.58 & 0.01 \\
\hline complete resection & 9.34 & 3.76 & 2.48 & 0.01 \\
\hline
\end{tabular}




\begin{tabular}{|c|c|c|c|c|}
\hline hippocampal sclerosis & -9.61 & 11.35 & -0.85 & 0.4 \\
\hline glial scar & -10.65 & 11.64 & -0.92 & 0.36 \\
\hline MCD & -16.69 & 10.68 & -1.56 & 0.12 \\
\hline TSC & -30.83 & 11.38 & -2.71 & 0.01 \\
\hline vascular lesion & 4.03 & 15.83 & 0.25 & 0.8 \\
\hline hypothalamic hamartoma & -13.37 & 12.88 & -1.04 & 0.3 \\
\hline normal histopathology & -14.47 & 14.44 & -1 & 0.32 \\
\hline tumour & -2.07 & 10.84 & -0.19 & 0.85 \\
\hline Model Characteristics & value & & & \\
\hline observations & 154 & & & \\
\hline error degrees of freedom & 139 & & & \\
\hline estimated dispersion & 268 & & & \\
\hline F-statistic vs. constant model & 8.54 & & & \\
\hline$p$ value & $<0.001$ & & & \\
\hline r2 effect size & 0.46 & & & \\
\hline \multicolumn{5}{|c|}{ C: Multiple regression based on the general linear model of IQ/DQ change } \\
\hline Variable & Estimate & SE & t statistics & p value \\
\hline intercept & 10.91 & 3.28 & 3.33 & 1 \\
\hline TLE & -13.53 & 3.3 & -4.09 & $<0.001$ \\
\hline XTLE & -12.38 & 3.26 & -3.8 & $<0.001$ \\
\hline age at surgery & 0.44 & 0.14 & 3.18 & 2 \\
\hline Model Characteristics & value & & & \\
\hline observations & 154 & & & \\
\hline error degrees of freedom & 150 & & & \\
\hline estimated dispersion & 84.8 & & & \\
\hline F-statistic vs. constant model & 8.07 & & & \\
\hline
\end{tabular}




\begin{tabular}{|l|r|r|r|l|}
\hline$p$ value & $<0.001$ & & & \\
\hline$r 2$ effect size & 0.14 & & & \\
\hline
\end{tabular}

1 
Table 5 (on next page)

Summary of post-hoc tests.

(A) Post-hoc tests for variables associated with presurgical IQ/DQ. (B) Post-hoc tests for variables associated with postsurgical IQ/DQ. FCD: focal cortical dysplasia, MCD: malformations of cortical development, TSC: tuberous sclerosis complex, HS: hippocampal sclerosis, df:degrees of freedom 


\begin{tabular}{|l|l|l|l|l|l|l|}
\hline A: Post-hoc tests for IQ/DQ_presurgical \\
\hline variable name & mean difference & median difference & $\begin{array}{l}\text { p- } \\
\text { value }\end{array}$ & $\begin{array}{l}\text { effect } \\
\text { size }\end{array}$ & Fstat & df \\
\hline glial scar_tumour & $-22.79(-41.92,-3.67)$ & $-20(-36,-8)$ & $<0.001$ & 0.189 & 16.583 & 66 \\
\hline MCD_tumour & $-13.84(-24.72,-2.97)$ & $-14(-20,-7)$ & $<0.001$ & 0.130 & 17.613 & 110 \\
\hline TSC_tumour & $-29.23(-45.28,-29.23)$ & $-31(-39,-21)$ & $<0.001$ & 0.355 & 41.261 & 72 \\
\hline HS_tumour & $-12.86(-25.82,-12.86)$ & $-14(-22,-5)$ & 0.001 & 0.109 & 11.683 & 86 \\
\hline FCD1_FCD3B & $-19.46(-35.02,-3.89)$ & $-22(-33,-8)$ & 0.001 & 0.208 & 12.815 & 44 \\
\hline FCD3A_FCD3B & $-17.70(-32.20,-3.19)$ & $-19(-28,-9)$ & $<0.001$ & 0.220 & 15.088 & 49 \\
\hline FCD3B_unspecified MCD & $20.42(1.28,39.57)$ & $21(5,34)$ & 0.006 & 0.168 & 8.664 & 37 \\
\hline TLE_hemi & $20.95(7.09,34.80)$ & $21(36,7)$ & 0.001 & 0.104 & 12.709 & 100 \\
\hline XTLE_hemi & $16.69(2.84,30.54)$ & $18(32,3)$ & 0.005 & 0.066 & 8.175 & 100 \\
\hline
\end{tabular}

\begin{tabular}{|l|l|l|l|l|l|l|}
\hline B: Post-hoc tests for IQ/DQ_postsurgical & & & \\
\hline & mean difference & median difference & $\begin{array}{l}\text { p- } \\
\text { value }\end{array}$ & effect size & Fstat & df \\
\hline variable name & $-20.69(-33.36,-8.02)$ & $-21(-27,-14)$ & $<0.001$ & 0.241 & 28.870 & 87 \\
\hline TSC_tumour & $-35.71(-53.29,-18.12)$ & $-35(-47,-24)$ & $<0.001$ & 0.457 & 49.766 & 57 \\
\hline HS_TSC & $22.33(3.10,41.55)$ & $21(8,35)$ & 0.001 & 0.221 & 12.379 & 39 \\
\hline hamartoma_tumour & $-23.25(-45.26,-1.24)$ & $-19(-36,-3)$ & 0.005 & 0.136 & 8.722 & 48 \\
\hline FCD1_FCD3B & $-26.55(-44.98,-8.13)$ & $-27(-41,-12)$ & $<0.001$ & 0.307 & 17.353 & 36 \\
\hline FCD3A_FCD3B & $-20.61(-35.34,-5.89)$ & $-20(-29,-7)$ & 0.005 & 0.180 & 9.133 & 36 \\
\hline unspecified MCD_FCD3B & $23.84(0.31,47.37)$ & $26(13,36)$ & 0.002 & 0.275 & 12.005 & 28 \\
\hline
\end{tabular}

